\title{
Early Differentiation of Retinal Ganglion Cells: An Axonal Protein Expressed by Premigratory and Migrating Retinal Ganglion Cells
}

\author{
Steven C. McLoon and Roxann B. Barnes \\ Department of Cell Biology and Neuroanatomy, University of Minnesota, Minneapolis, Minnesota 55455
}

\begin{abstract}
A monoclonal antibody, RA4, was developed that recognizes retinal ganglion cell axons in the mature retina. Between embryonic days 3 and 9, the RA4 antigen was associated with cell bodies in certain regions of the retina in addition to the ganglion cell axons. The RA4-positive cells were of 3 types: an apolar cell adjacent to the ventricular surface, a bipolar cell that spanned the thickness of the retina, and a monopolar cell in the ganglion cell layer. Evidence suggests that these cells are premigratory and migrating retinal ganglion cells. The expression of the RA4 antigen is the earliest indicator of ganglion cell differentiation yet reported. The existence of RA4-positive apolar cells along the outer surface of the retina suggests that the ganglion cell phenotype is expressed as soon as the cell becomes postmitotic. Approximately $20 \%$ of the migrating ganglion cells were in pairs. The paired cells most likely arose from the terminal division of a germinal cell. One possibility suggested by these data is that a ganglion cell-specific germinal cell arises from a pluripotent germinal cell.

Immunoblots and other analyses revealed the RA4 antigen to be a $140 \mathrm{kDa}$ cytoplasmic protein in the retina. RA4 also recognized many long tract axons in the brain. In the brain, the RA4 epltope was observed on proteins with at least 7 different molecular weights. Evidence suggests that different cell types may express the RA4 antigen with slightly different molecular weights.
\end{abstract}

The sequence of ganglion cell differentiation in the vertebrate retina has been fairly well described (Ramón y Cajal, 1911, 1929; Morest, 1970; Hinds and Hinds, 1974; Prada et al., 1981). In the scheme currently most accepted, a ventricular cell, adjacent to the retinal ventricle or external surface, undergoes mitotic division. This gives rise to apolar cells. An apolar cell extends a process through the thickness of the retina that joins the inner limiting membrane. ${ }^{1}$ This results in a bipolar cell. The nucleus moves within the process towards the inner surface of

\footnotetext{
Received June 1, 1988; revised Aug. 4, 1988; accepted Aug. 29, 1988.

We would like to thank Ms. Kathy Ensrud for her advice and assistance and Drs. Paul Letourneau, Dick Linck, and Linda McLoon for critically reading the manuscript. This work was supported by NIH Grant EY05371 and the Graduate School of the University of Minnesota.

Correspondence should be addressed to Steven C. McLoon, Department of Cell Biology, University of Minnesota, 4-135 Jackson Hall, 321 Church St. SE, Minneapolis, MN 55455.
}

Copyright (C) 1989 Society for Neuroscience 0270-6474/89/041424-09\$02.00/0

\footnotetext{
${ }^{1}$ The inner limiting membrane of the retina is continuous with the external limiting membrane of the rest of the CNS. The outer surface of the neural retina lines a ventricle during development, and this ventricle is continuous with the ventricular system of the brain.
}

the retina. The bipolar cell breaks its attachment with the ventricular surface and extends an axon from its vitreal process into the optic fiber layer. Once the ventricular process is retracted the cell becomes a monopolar cell with its nucleus positioned in the developing ganglion cell layer. Finally, the monopolar cell extends dendrites becoming a multipolar ganglion cell.

The point in this developmental scheme at which a ventricular cell first becomes committed to the ganglion cell phenotype or when the first ganglion cell characteristics are expressed remains unclear. Hinds and Hinds (1974), in an electron microscopic study of the developing mouse retina, reported that the migration of the centrioles, which corresponded in time with the detachment of the ventricular process by the bipolar cell, was the first morphological change that could be definitively attributed to differentiation of a ganglion cell from a ventricular cell. Morest (1970) went so far as to suggest that interaction of a ventricular cell with the inner limiting membrane at the vitreal surface may be required for development of the ganglion cell phenotype.

A monoclonal antibody, RA4, that recognizes a retinal ganglion cell antigen in chick is described here. RA4 appears to bind to retinal ganglion cells as early as their apolar stage of development. This suggests that ganglion cells begin to differentiate immediately after their last cell division. Certain results also suggest that at least some dividing ventricular cells may be committed to a ganglion cell lineage.

The presence of the RA4 antigen was also examined by immunohistochemistry and immunoblot in the developing chick brain. The antigen is expressed by most, if not all, long tract axons, although it may have a different molecular weight on different axons.

\section{Materials and Methods}

Animals. Fertilized chicken eggs, pathogen-free White Leghorn crossed with Rhode Island Red, were obtained from the University of Minnesota Poultry Research Center. Eggs were incubated at $37^{\circ} \mathrm{C}$ in an egg incubator. Some embryos were removed from the shell after $3 \mathrm{~d}$ of incubation and placed in culture chambers (McLoon, 1985). Cultured embryos had both eye vesicles destroyed with a microcautery. The eyeless embryos were maintained in a forced-draft tissue culture incubator at $37^{\circ} \mathrm{C}, 95 \%$ relative humidity, and $1 \% \mathrm{CO}_{2}$.

$\mathrm{Balb} / \mathrm{c}$ mice, 4-6 weeks old, were obtained from the University of Minnesota's colony and used in the production of monoclonal antibodies.

Monoclonal antibody production. Tecta were dissected from eyeless chick embryos at $10 \mathrm{~d}$ of incubation (E10) and homogenized. Two mice received a $0.1 \mathrm{ml}$ injection of the homogenate into a tail vein and a 0.4 $\mathrm{ml}$ intraperitoneal (i.p.) injection of the homogenate mixed 1:1 (vol/ vol) with Freund's complete adjuvant. Two days later the mice received an i.p. injection of cyclophosphamide $(40 \mathrm{mg} / \mathrm{kg}$ ) (Matthew and Sandrock, 1987). After 2 weeks the mice were immunized with tecta from normal E10 chick embryos administered as described above for the eyeless tecta. The mice were boosted twice at 3 week intervals. Three 
d after the final booster, the spleens were removed from the mice. Hybridomas were prepared with NS-1 myeloma cells according to standard protocols (Kohler and Milstein, 1976; Lemmon and McLoon, 1986). Hybridoma culture supernatants were screened by immunoh istochemistry on sections of E10 chick retina and brain. The antibody, RA4, was selected for further analysis based on its selective binding to ganglion cell axons. The RA4-producing colony was subcloned twice by limiting dilution and then expanded in $75 \mathrm{~cm}^{2}$ flasks. Culture supernatant was harvested, and the antibodies were partially purified from the medium by ammonium sulfate precipitation. After desalting in a Centricon (Amicon), the antibody was dissolved in PBS at $10 \times$ its original concentration. This was used at a 1:100 dilution in all the following procedures.

Immunohistochemistry. Chicks of various ages from E6 to adult were perfused with $4 \%$ paraformaldehyde in phosphate buffer. Embryos on E3-4 were fixed by immersion in the same fixative. The eyes and brains of the chicks were cryoprotected in $20 \%$ sucrose/phosphate buffer overnight, embedded in a homogenate of brain, and sectioned at $12 \mu \mathrm{m}$ in a cryostat. The sections were mounted on glass slides, rinsed in PBS, and blocked with $10 \%$ normal goat serum $/ 0.3 \%$ Triton X-100/PBS. The tissue was then incubated for $1.5 \mathrm{hr}$ in RA4/PBS, rinsed in PBS, and incubated for $1 \mathrm{hr}$ in goat anti-mouse IgG conjugated to fluorescein isothiocyanate (Cappel). The slides were examined and photographed with an epifluorescence microscope.

Adjacent sections were processed as controls. These sections were incubated in fresh culture medium in place of the primary antibody and processed as described above. No fluorescence significantly above background levels was observed in these sections.

Sections adjacent to some of those processed for immunohistochemistry were also stained for $3 \mathrm{~min}$ with $0.0001 \%$ Nuclear yellow (wt/vol) in PBS to allow counting of mitotic figures in the region of RA4-positive cells.

Retinal explant cultures. Retinas were dissected from E6 chick embryos. The retinas were cut into pieces approximately $0.5 \mathrm{~mm}^{2}$ in $F 12$ medium (Gibco). The fragments of retina were transferred to laminincoated glass coverslips (Kapfhammer et al., 1986) in F12 medium supplemented according to Bottenstein (Bottenstein et al., 1980) with the addition of $2 \mathrm{~mm}$ glutamine and $0.005 \mathrm{mg} / \mathrm{ml}$ gentamicin. The cultures were maintained at $37^{\circ} \mathrm{C}$ and $5 \% \mathrm{CO}_{2}$. After $2 \mathrm{~d}$ in culture, the explants were processed for immunochemistry. The RA4 antibody was added to half the cultures for $1.5 \mathrm{hr}$. These explants were then rinsed in medium and fixed with $4 \%$ paraformaldehyde/phosphate buffer $(\mathrm{pH} \mathrm{7.3)}$. The other half of the cultures were fixed with paraformaldehyde, permeablized in $0.3 \%$ Triton X-100/PBS for $10 \mathrm{~min}$, and incubated in RA4 for $1.5 \mathrm{hr}$. All cultures were rinsed in PBS and incubated in secondary antibody as described above.

Live cultures stained with the RA4 antibody were negative, and thus served as controls.

Immunoblots. Retinas or tecta were dissected from embryos at $2 \mathrm{~d}$ intervals from E4 to E18 and from an adult chicken. Whole adult chicken brain lacking the tecta was also used. The tissue was homogenized in an SDS sample buffer that contained 6\% 2-mercaptoethanol, boiled for $5 \mathrm{~min}$, and run on a $5 \%$ SDS-PAGE (Laemmli, 1970). The proteins were transferred from the polyacrylamide gel to nitrocellulose electrophoretically (Towbin et al., 1979). Strips of the blots were blocked with $10 \% \mathrm{BSA} / \mathrm{PBS}$, incubated for $2 \mathrm{hr}$ in RA4/PBS, rinsed in PBS, and incubated in goat anti-Inouse IgG conjugated to HRP (Sigma) for $2 \mathrm{hr}$. After rinsing in PBS, the blot strips were incubated in diaminobenzidine and hydrogen peroxide. A mixture of prestained proteins with known molecular weights from 84 to $180 \mathrm{kDa}$ (Sigma) was run in a parallel lane of each gel.

\section{Results}

A monoclonal antibody, RA4, was prepared that recognizes an antigen associated with certain cell types in the developing and mature retina as well as some cellular elements of the brain. The initial characterization of this antigen concentrated on immunohistochemical localization in the primary visual system and a preliminary biochemical analysis.

\section{Retina immunohistochemistry}

The distribution of the RA4 antigen in the retina was examined by immunohistochemistry at approximately $3 \mathrm{~d}$ intervals from
E3 to adult (2 months posthatch). Staining with the RA4 antibody was found in the retina at all ages examined, but the distribution of the antigen showed distinct changes during development. Early on E3, the RA4 antigen was expressed on some round or apolar cells within the outer cell layer or mitotic region of the retina. RA4 also appeared to stain bipolar cells that spanned the retina from the vitreal (inner) to the ventricular (outer) surface. The nuclei of the bipolar cells were variably positioned between the vitreal and ventricular surfaces. Late on E3 and on E4, an additional RA4-positive cell type was seen (Fig. 1A). These were unipolar cells positioned towards the vitreal surface of the retina, presumably in the developing ganglion cell layer. These cells each had a single process that extended along the inner surface of the retina, which appeared to constitute the early optic fiber layer. All cells that expressed the RA4 antigen were confined to a small region of central retina at these early stages. No mitotic figures were encountered that were positive for RA4.

A similar staining pattern as that seen in central retina on $\mathrm{E} 3$ was encountered in more peripheral retina on E6 and E9 (Fig. $1 B$ ). Round cells in the mitotic layer, bipolar cells spanning the thickness of the retina, and unipolar cells in the ganglion cell layer all expressed the RA4 antigen. In all central regions of the retina at these ages, the optic fiber layer was positive for RA4, but there was no staining on any cells or in any deeper layers of the retina. The very most peripheral margin of the retina did not stain. Again, no mitotic figures appeared positive for RA4.

The cells that were positive for RA4 very often appeared as an adjoining pair (arrow in Fig. $1 B$ ). This was readily evident on casual inspection of the retinas, but an attempt was made to quantify this phenomenon. One hundred RA4-positive apolar or bipolar cells in each of 3 E3.5 and 3 E6 eyes (for a total of 600 cells) were scored as paired or unpaired. Just under $21 \%$ of the RA4-positive cells were paired. There was no significant difference between the 2 ages. In order to determine whether this frequency of RA4-positive cell pairs was the result of adjacent germinal cells dividing, the incidence of paired mitotic figures was determined. Adjacent sections to those used in the RA4-positive cell count were stained to show nuclei with $\mathrm{Nu}$ clear yellow. Paired and unpaired metaphase and anaphase cells in the same retinal areas that contained RA4-positive cells were counted. All these cells were along the ventricular surface of the developing retina. Slightly more than $1 \%$ of the metaphase/ anaphase cells were next to another metaphase/anaphase cell. This suggests that pairs of RA4-positive cells do not arise as a result of the division of 2 adjacent germinal cells. It is more likely that paired RA4-positive cells are the 2 daughter cells resulting from the division of a single germinal cell.

RA4 staining in the retina was confined to the optic fiber layer at all ages examined past E9 (Fig. 1C).

\section{Brain immunohistochemistry}

RA4-positive axons could be traced from the eye into the brain beginning as early as E4. In addition to the staining on retinal axons, many long tract axons in both the central and peripheral nervous system were RA4 positive. The analysis presented here is confined to the staining pattern in the optic tectum. Prior to E6 there was little of the RA4 antigen present in the tectum that could be detected by immunohistochemistry. On E6, RA4-positive fibers were present in stratum opticum at the rostroinferior margin of the tectum. Presumably these were the first retinal axons to arrive in the tectum (McLoon, 1985). On E9 a broad 


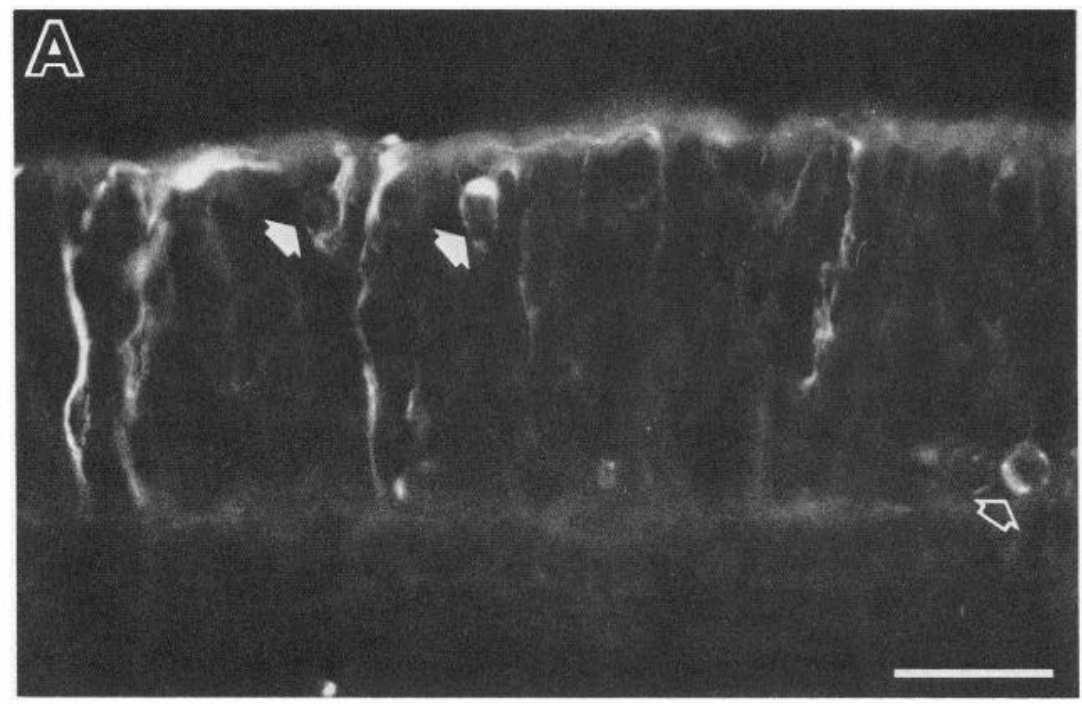

Figure 1. Fluorescence photomicrographs of sections from retina stained immunohistochemically with the RA4 antibody. The vitreal (inner) surfaces are towards the top and the ventricular (outer) surfaces are towards the bottom in each micrograph. $A$, Central retina from an E3.5 embryo. An apolar cell is present at the far right near the ventricular surface (open arrow). Several bipolar cells span the thickness of the retina such as the one to the far left. Unipolar cells (closed arrows) near the vitreal surface appear to extend processes into the optic fiber layer. $B$, Peripheral retina from an E9 embryo. A pair of RA4-positive cells is in the lower center (arrow). Peripheral retina is towards the left; central retina is towards the right. $C$, Retina from an E12 embryo. The optic fiber layer along the vitreal surface is RA4 positive in each of these sections. Scale bars, $50 \mu \mathrm{m}$.
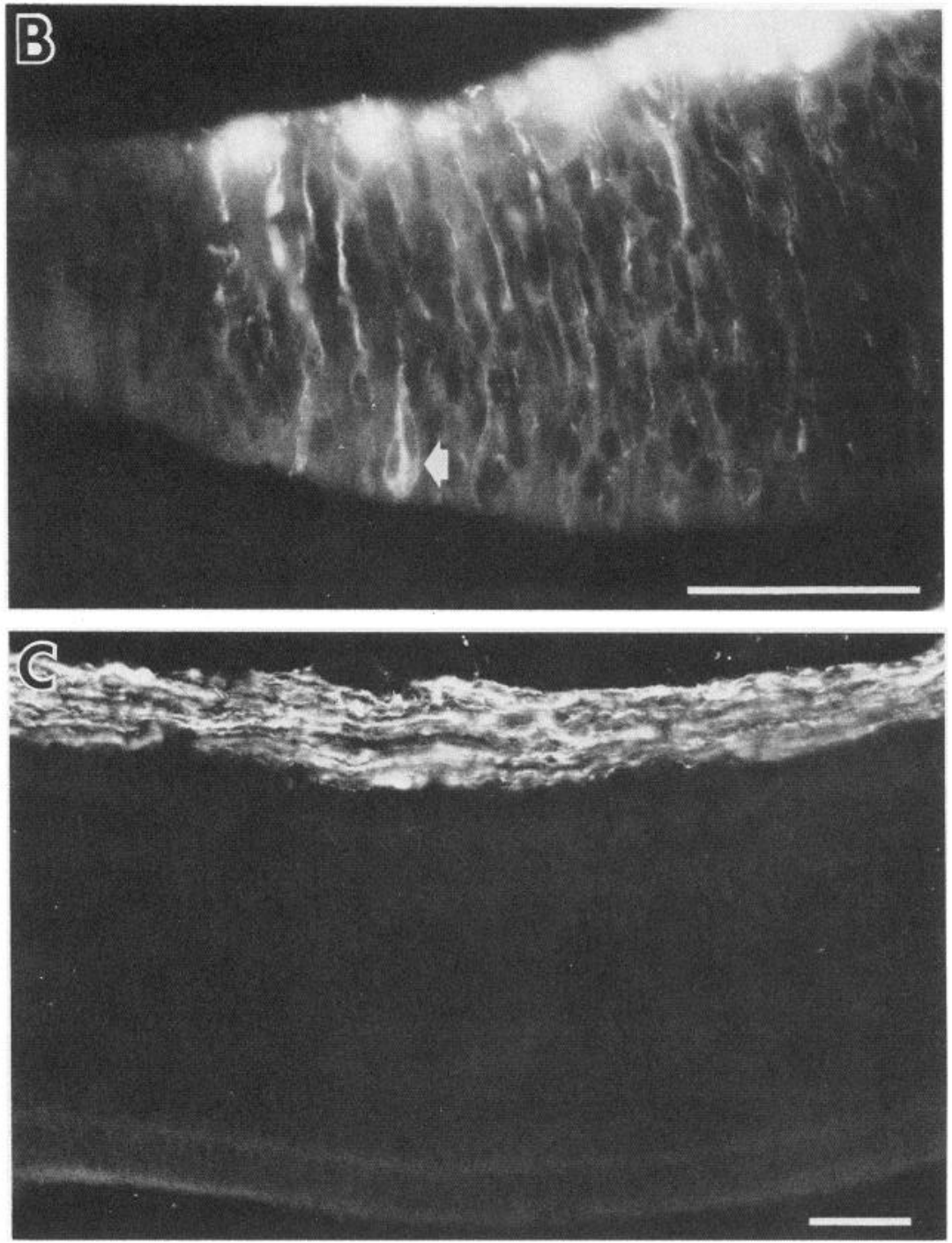

band of RA4-positive fibers was present in the inner half of layer $\mathrm{i}$ of the tectum (tectal layers are according to LaVail and Cowan, 1971). The RA4-positive fibers, which first appeared in the stratum opticum on E6, had covered more of the tectal surface by E9 (Fig. $2 A$ ). Their distribution over the tectum matched that of the retinal axons as demonstrated by anterograde tract tracing techniques (McLoon, 1985). To further support that the RA4 antigen in the stratum opticum was associated 

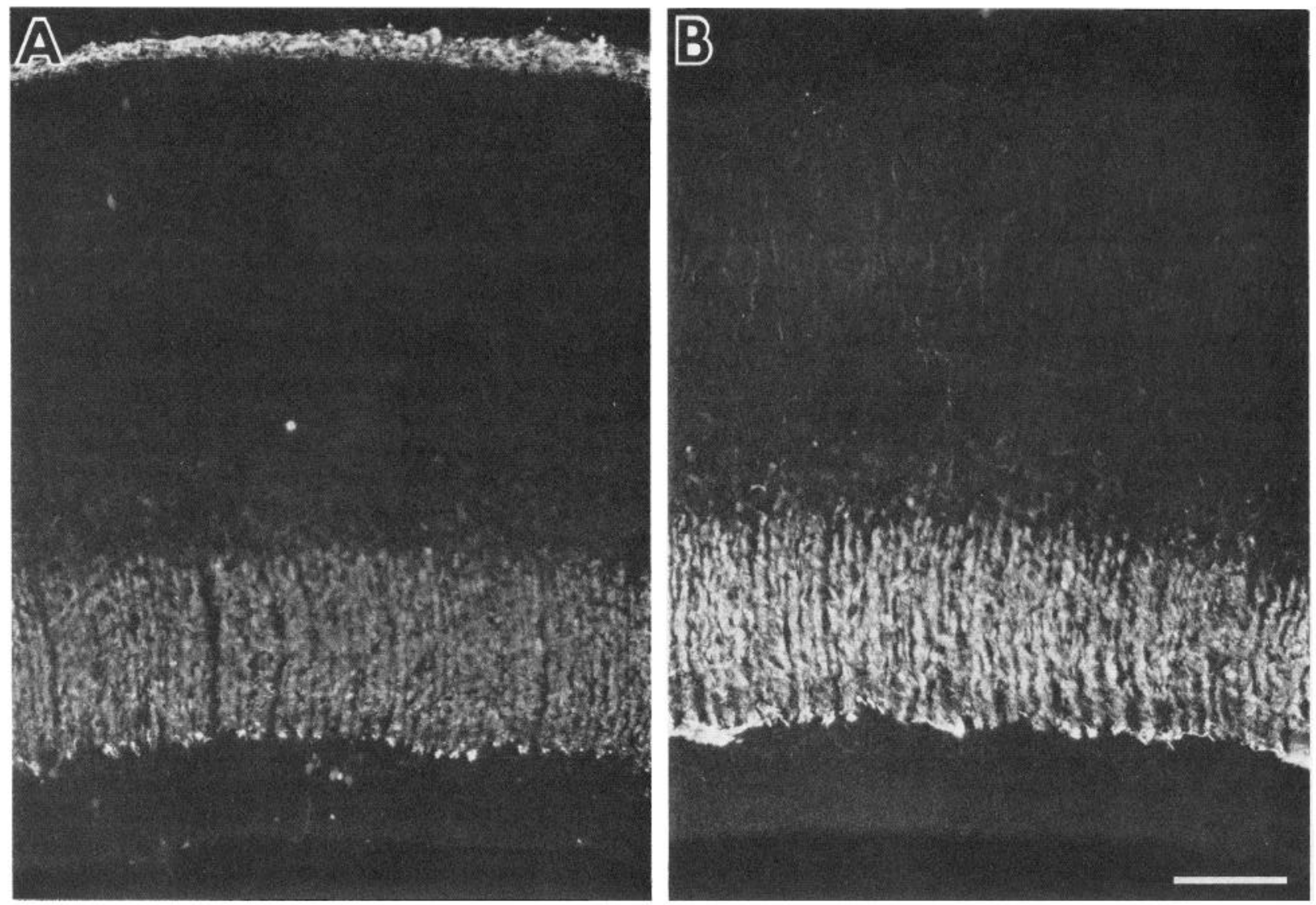

Figure 2. Fluorescent photomicrographs of sections E9 tectum from a normal $(A)$ and an eyeless $(B)$ chick embryo stained with the RA4 antibody. In the section of normal tectum the stratum opticum (at the top) is RA4 positive. In the section of eyeless tectum, the staining in the stratum opticum is absent. Both sections show staining in layer i deep in the tectum. Scale bar, $100 \mu \mathrm{m}$.

with retinal axons, eyeless $\mathrm{E} 9$ chick embryos were processed for immunohistochemistry. The RA4 staining in the deep layer of tectum was present in the eyeless embryos; however, the staining in the optic fiber layer was absent (Fig. 2B). By E12, there were 3 populations of RA4-positive fibers present in the tectum (Fig. 3). These were in layers iii, iv, and stratum opticum (or xii). During all these developmental ages there were some radially oriented bipolar cell bodies that stained faintly with RA4, but these cells never showed the intensity of staining exhibited by cells in the early retina. At least 4 distinct layers of RA4-positive fibers could be seen in the tectum from E18 through the adult (Fig. 4). From the inside towards the outside these fibers were in the stratum griseum periventriculare, stratum album centrale, stratum griseum centrale, and stratum opticum. There were also a few RA4-positive processes scattered through the stratum griseum et fibrosum superficiale (SGFS). However, the density of RA4 positive processes in the SGFS did not begin to match the density of retinal axons present in these layers (McLoon, 1985).

\section{Retinal explant immunohistochemistry}

Explants were prepared from E6 chick retina and processed for immunohistochemistry using the RA4 antibody. A considerable number of neurites grew out from the retinal explants after $2 \mathrm{~d}$ in vitro (Fig. 5, $A, C$ ). Living explants exposed to the RA4 antibody, then fixed and treated with the secondary antibody, had faint fluorescence in the explant but no staining of the neurites (Fig. $5 B$ ). Cultures that were fixed, permeablized with the detergent Triton X-100, and then stained with the RA4 antibody exhibited bright staining in all the neurites (Fig. $5 D$ ). In some cases, the staining clearly extended into the lamellipodia at the end of the growth cones (arrow in Fig. 5D). At higher magnification the staining within the neurites appeared to be a meshwork of fine fibrils (not shown).

\section{Immunoblots}

Retinal and tectal tissues of different ages were processed for SDS-PAGE. The gels were transblotted on to nitrocellulose, and the blots were reacted with the RA4 antibody and a secondary antibody coupled to HRP (Fig. 6). Retinal tissue at all ages examined from E4 to adult resulted in one sharply focused RA4positive band with an approximate $M_{r}$ of 140,000 . No additional RA4-positive bands were found with retinal tissue at any age. Boiling the tissue for $20 \mathrm{~min}$ prior to running the gel abolished all staining of the transblot. Omission of the 2-mercaptoethanol from the sample buffer did not alter the mobility of the RA4 antigen. The RA4 antigen was extracted from E10 retinas with several nonionic detergents (i.e., Tween-20, NP-P40, Triton $\mathrm{X}-100$ ) or a low-salt buffer, as well as SDS.

Tectal tissue showed variations in the number of RA4-positive bands in the immunoblot, variations that were dependent on the age of the embryo. At E4 no RA4-positive bands were found. At E6 a faint band at $140 \mathrm{kDa}$ was variably encountered. At E8 and E10, two bands were found at 140 and $125 \mathrm{kDa}$. At E12 and E14, tectal tissue gave 3 bands at 150,140, and 125 


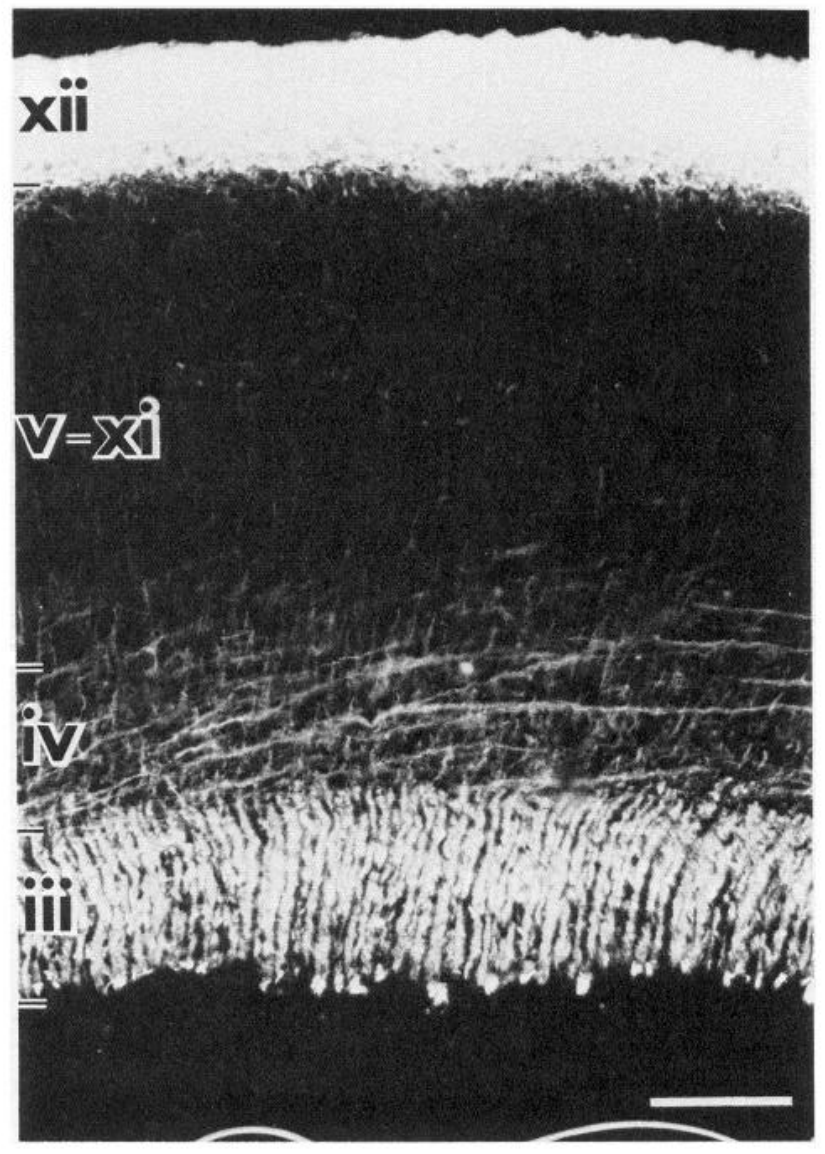

Figure 3. Fluorescent photomicrograph of a section of E12 tectum stained with the RA4 antibody. Axons in stratum opticum (layer xii) and layers iii and iv are RA4 positive. Scale bar, $100 \mu \mathrm{m}$.

$\mathrm{kDa}$. One additional band just below the $150 \mathrm{kDa}$ band $(\sim 147$ $\mathrm{kDa}$ ) was present from E15 through the adult. The effect of reduction and boiling of the tectal tissue was the same as with retinal tissue. Antibodies eluted from the $140 \mathrm{kDa}$ band of an immunoblot of E12 retina recognized all 3 bands in a blot of E12 tectum. This virtually eliminates the possibility that the antibody is polyclonal.

The RA4 antibody recognized 7 bands in blots of whole adult chicken brain (that lacked both tecta). The bands had approximate masses of $150,145,140,137,128,125$, and $120 \mathrm{kDa}$. When processed on the same blot the $145 \mathrm{kDa}$ band from whole brain did not match the migration of the $147 \mathrm{kDa}$ band from adult tectum.

\section{Discussion}

A monoclonal antibody, RA4, was developed that recognizes an antigen in discrete regions of the mature and developing chick retina. In the mature retina, RA4 immunoreactivity was confined to the optic fiber layer. Between embryonic days 3 and 9, RA4 staining was associated with cells in certain regions of the retina in addition to the optic fiber layer. The RA4-positive cells were of 3 types: an apolar cell adjacent to the ventricular surface, a bipolar cell that spanned the thickness of the retina, and a monopolar cell in the ganglion cell layer. In E3-4 embryos, these RA4-positive cells were found in central retina. In older embryos up through E9, these cells were found in progressively more peripheral retinal areas.

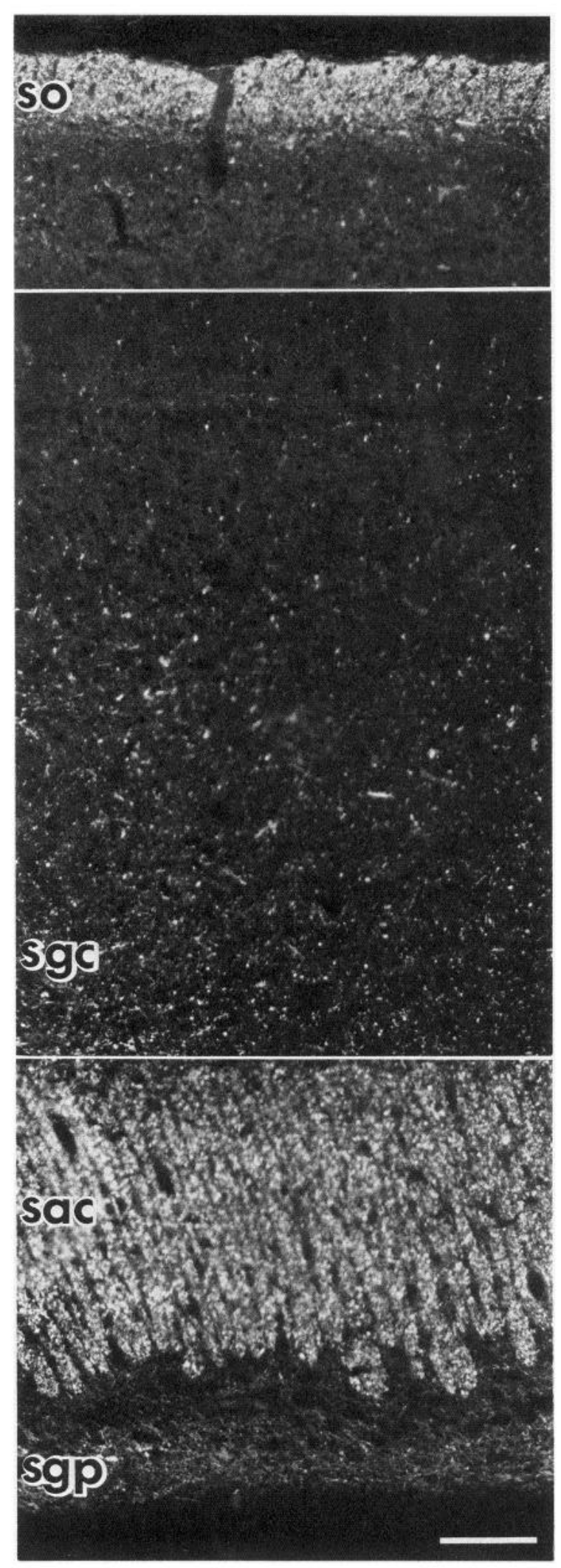

Figure 4. Fluorescent photomicrograph of a section of adult tectum stained with the RA4 antibody. Axons in stratum opticum (so), stratum griseum centrale $(s g c)$, stratum album centrale $(s a c)$, and stratum griseum periventriculare $(s g p)$ are RA4 positive. Scale bar, $100 \mu \mathrm{m}$. 

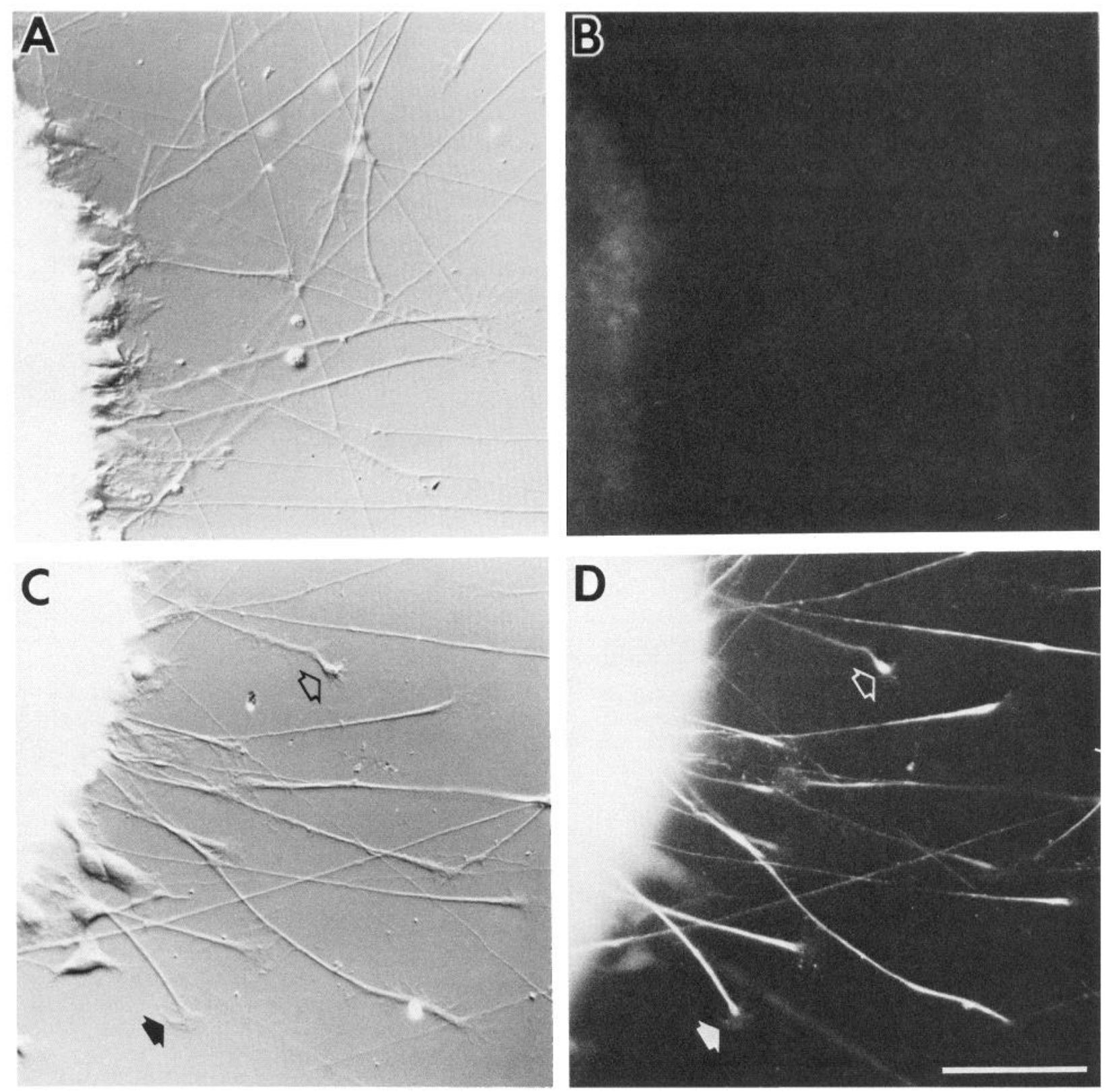

Figure 5. Retinal explants stained with the RA4 antibody and photographed with differential interference microscopy to show all processes (left) and fluorescence microscopy to show labeling with the RA4 antibody (right). The top explant $(A, B)$ was living when exposed to the antibody and shows no staining. The lower explant $(C, D)$ was fixed and its membranes permeablized before being exposed to the antibody. It shows staining of the neurites, including the growth cones (arrows). Scale bar, $50 \mu \mathrm{m}$.

There is little doubt that the RA4 immunoreactivity in the optic fiber layer was associated with the ganglion cell axons. The axons are the major cellular component of this layer, and the staining pattern was consistent with the distribution of the axons. The RA4-positive ganglion cell axons could also be traced into the brain and along the optic tract to the various visual nuclei. In eyeless embryos, this RA4 staining was absent in the visual pathway. The neurites that extend from retinal explants in culture originate from the ganglion cells (Johns et al., 1978), and these too expressed the RA4 antigen.

The RA4 antigen in the early developing retina that was outside the optic fiber layer also appeared to be confined to ganglion cells. Four lines of evidence support this conclusion. First, the developmental age and retinal position of RA4-positive cells outside the optic fiber layer correlates with the time and position of retinal ganglion cell genesis and migration based on thymidine autoradiography (Fujita and Horii, 1963; Kahn, 1973, 1974; McLoon, 1984). Second, the different morphologies of the cells, as identified by immunohistochemistry in the early developing retina, match those of the different stages of ganglion cell development as proposed by others (Ramón y Cajal, 1911, 1929; Morest, 1970; Hinds and Hinds, 1974; Prada et al., 1981). Third, when ganglion cells are becoming postmitotic in the peripheral retina, other cell types are becoming postmitotic and undergoing migration in more central areas of the retina (Fujita and Horii, 1963; Kahn, 1974). Outside the optic fiber layer, cells in these more central retinal areas are not RA4 positive. Furthermore, no RA4-positive cells are present outside the optic 


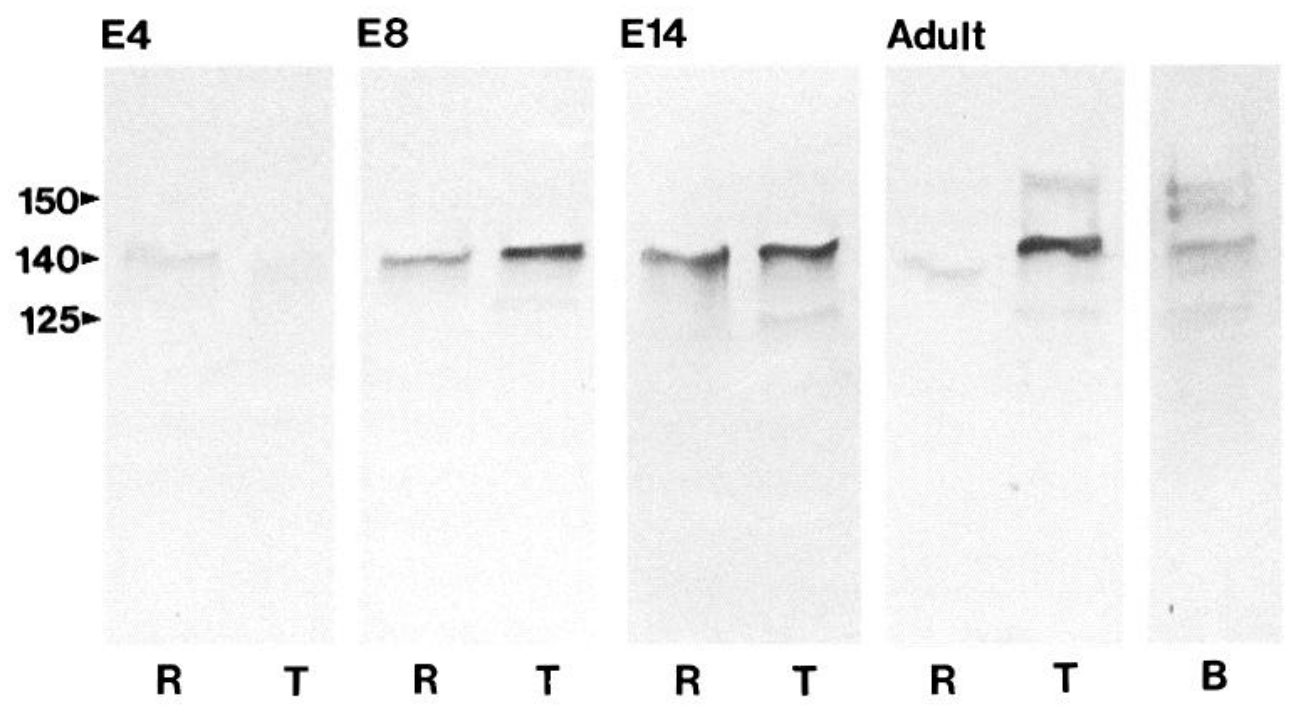

Figure 6. Immunoblots of extracts from retina $(R)$, tectum $(T)$, and whole brain lacking tectum $(B)$ from E4 to adult chicks processed with the RA4 antibody. Molecular weight indicators along the left side are in $\mathrm{kDa}$. fiber layer after the last ganglion cells have divided and migrated. The last ganglion cells are generated on E10 (Kahn, 1973; McLoon, 1984). It may take an additional day for these cells to migrate up to the ganglion cell layer. No migrating RA4-positive cells were present on E12, even though many nonganglion cell types were still dividing and migrating at this age in most areas of the retina. Fourth, monopolar cells, cells clearly ending migration, were only found in the ganglion cell layer, and many of these had obvious axons extending into the optic fiber layer. It is somewhat surprising that displaced ganglion cells were not identified by RA4. It may be that not all ganglion cells express the RA4 antigen, or the displaced ganglion cells may develop as the result of a secondary migration of cells from the ganglion cell layer after the expression of the RA4 antigen has become more restricted. It cannot be ruled out that some of the RA4positive cells are amacrine cells that undergo a stage of maturation in which they resemble ganglion cells. There is some evidence for such a sequence in amacrine cell development (Hinds and Hinds, 1983). Thus, the evidence suggests that the majority of RA4-positive cells outside the optic fiber layer were premigratory and migrating ganglion cells. Since no dividing cells were RA4 positive, it would appear that these cells were postmitotic.

If the RA4 antigen within the retina is a unique molecule of retinal ganglion cells, then the expression of the RA4 antigen is the earliest ganglion cell characteristic to develop yet reported. As described at the beginning of this paper, a postmitotic cell that differentiates into a ganglion cell passes through a series of stages: an apolar cell adjacent to the ventricular surface, a bipolar cell that spans the thickness of the retina, a monopolar cell in the ganglion cell layer, and finally a multipolar cell (Morest, 1970; Prada et al., 1981). The earliest ganglion cell characteristic previously identified was during retraction of the ventricular process by the bipolar cell (Hinds and Hinds, 1974). Since the RA4 antigen is expressed by all these cell stages, including apolar cells along the ventricular surface, it appears that the ganglion cell phenotype is expressed by cells as soon as they become postmitotic. Thus, it would appear that interaction of a postmitotic cell with the vitreal portion of the retina is not essential for inducing the ganglion cell phenotype as has been previously suggested (Morest, 1970). Such early differentiation of the gan- glion cell phenotype might even suggest that the cell's fate was determined prior to its final division.

Approximately $20 \%$ of the migrating RA4-positive ganglion cells appeared to be closely apposed to a second RA4-positive cell. This percentage could actually be a low estimate since some RA4-positive cells may have had an adjoining RA4-positive cell outside the plane of section. No effort was made to determine this through serial section analysis. Other investigators have observed pairs of cells differentiating into ganglion cells (Sechrist, 1969; Hinds and Hinds, 1974). There are 3 explanations most likely to account for the cell pairs. First, adjacent germinal cells may have divided at the same time, giving rise to adjacent daughter cells that both differentiated into ganglion cells. This seems unlikely since we almost never encountered $(\sim 1 \%) 2$ adjacent mitotic profiles in stained sections of retina. Second, some germinal cells may be RA4 positive and give rise to 2 RA4-positive cells, one of which continues as a germinal cell. This also seems very unlikely since no RA4-positive cells were found undergoing mitosis. It seems even more unlikely that a cell would synthesize a $140 \mathrm{kDa}$ protein and then completely catabolize it in order to undergo another division. Third, a germinal cell could undergo its terminal cell division giving rise to 2 cells, both of which differentiate into RA4-positive ganglion cells. However, this too seems unlikely in light of recent analyses of retinal cell lineage using retroviruses or rhodamine-labeled cells (Turner and Cepko, 1987; Wetts and Fraser, 1988). These studies suggest that an individual germinal cell can give rise to cells in all layers of the retina. Since ganglion cells are the first cells to arise (Fujita and Horii, 1963; Kahn, 1974), one would not expect to see 2 ganglion cells produced by the terminal division of a pluripotent germinal cell. It is still possible that some pluripotent germinal cells do randomly withdraw from the mitotic cycle early in retinal development. Another possibility is that a common germinal cell gives rise to determined germinal cells. The determined germinal cells could undergo a very limited number of divisions with all progeny differentiating into ganglion cells, and the paired RA4-positive cells would represent the terminal divisions of such determined germinal cells. In this regard, it is interesting to note that there is a region of cell division in the retina peripheral to where the ganglion cells are generated (far left in Fig. 1B). Division of pluripotent 
germinal cells in this region could give rise to determined germinal cells. One aspect of this scheme is supported by an analysis of germinal cell renewal in the developing chick retina (Dutting et al., 1983). It was shown that during early retinal development (at least until E7) more than half the cells resulting from cell division were still capable of dividing. This means that some cell divisions gave rise to 2 dividing cells. An analysis of mosaic compound eyes showed that progeny of dividing cells remained restricted to a single layer of retina (O'Gorman et al., 1987). This also supports the suggestion of committed germinal cells. The possibility of cells dividing that are committed to a neuronal phenotype is not a novel idea. In the sympathetic nervous system, neurons that have already differentiated have been shown to undergo division (Rothman et al., 1978, 1980; Ciment and Weston, 1982; Rohrer and Thoenen, 1987). Also, cells in the mitotic layer of the developing chick spinal cord were shown to express neurofilament proteins (Tapscott et al., 1981). It was concluded that these were dividing cells that had begun to differentiate a neuronal phenotype. However, the possibility that these were postmitotic premigratory neurons was not considered.

Immunohistochemistry using RA4 on tissue sections, particularly with the early developing retina, showed cytoplasmic staining in cells cut in cross scction (Fig. 1A). Howcver, it was not clear whether the RA4 antigen was also expressed on the cell surface. In order to determine whether the RA4 antigen is a cell surface component, live retinal explants were processed for immunochemistry with RA4. The antibody failed to bind to live axons in culture, while fixed axons permeablized with detergent stained very brightly with the antibody. This shows that the RA4 antigen is intracellular.

Preliminary biochemical characterization suggests that the RA4 antigen in the retina is a protein with a molecular weight of 140,000 . The molecular weight was determined by comparing the relative mobility of the antigen with SDS-PAGE to several protein standards as detected in immunoblots. Since the antigen was heat sensitive, it is probably a protein or glycoprotein. Based on the sharpness of the band on the immunoblots, the antigen must have minimal glycosylation (Goding, 1986). Since the relative mobility of the antigen was not influenced by reduction, it probably lacks interchain disulfide bonds. The antigen extracted very easily (i.e., with a low-salt buffer), which suggests that it is not membrane bound. At this time no effort has been made to compare the RA4 antigen to any known molecules. Given these biochemical characteristics and its fibrillar appearance with immunochemistry, it is probably a component of the cytoskeleton. Certain cytoskeletal elements have been shown by electron microscopy to redistribute from the cell body to the axon during ganglion cell development (Sechrist, 1969); the same redistribution of the RA4 antigen was seen.

The molecular weight of the RA4 antigen appeared to be much more variable in the brain than it was in the retina. The number of bands and their molecular weights on immunoblots varied for brain tissue depending on the brain region sampled and the age of the embryo. This has been best characterized for the tectum. At the earliest age examined no RA4 activity was found in the blots of tectum. In the adult, 4 bands were found with molecular masses of 125-150 kDa. Each of these bands appeared at a different time in development. As each new population of RA4-positive axons appeared in the tectum, a new band appeared in the immunoblot. Examination of the entire adult brain by immunoblot revealed as many as 7 bands with masses of 120-150 kDa. These data suggest that the RA4 antigen is present in many, if not all, long projecting axons and that it may have different apparent molecular weights in different populations of axons.

In summary, this study suggests that the RA4 antigen within the developing and mature retina is confined to retinal ganglion cells. The presence of the RA4 antigen on migrating and premigratory cells suggests that ganglion cells begin differentiation as soon as they become postmitotic. The presence of some paired migrating ganglion cells suggests that some ganglion cells arise from the terminal division of a germinal cell. One possible interpretation of these results is that some dividing cells in the retina are committed to a ganglion cell lineage.

\section{References}

Bottenstein, J. E., S. D. Skaper, S. Varon, and G. H. Sato (1980) Selective survival of neurons from chick embryo sensory ganglionic dissociates utilizing serum-free supplemented medium. Exp. Cell Res. 125: $183-190$.

Ciment, G., and J. A. Weston (1982) Early appearance in neural crest and crest-derived cells of an antigenic determinant present in avian neurons. Dev. Biol. 93: 355-367.

Dutting, D., A. Gierer, and G. Hansmann (1983) Self-renewal of stem cells and differentiation of nerve cells in the developing chick retina. Dev. Brain Res. 10: 21-32.

Fujita, S., and M. Horii (1963) Analysis of cytogenesis in chick retina by tritiated thymidine autoradiography. Arch. Histol. Jpn. 23: 359366.

Goding, J. W. (1986) Monoclonal Antibodies: Principles and Practice, Academic, San Diego, CA.

Hinds, J. W., and P. L. Hinds (1974) Early ganglion cell differentiation in the mouse retina: An electron microscopic analysis utilizing serial sections. Dev. Biol. 37: 381-416.

Hinds, J. W., and P. L. Hinds (1983) Development of retinal amacrine cells in the mouse embryo: Evidence for two modes of formation. J. Comp. Neurol. 213: 1-23.

Johns, P. R., A. M. Heacock, and B. W. Agranoff (1978) Neurites in explant cultures of adult goldfish retina derive from ganglion cells. Brain Res. 142: 531-537.

Kahn, A. J. (1973) Ganglion cell formation in the chick neural retina. Brain Res. 63: 285-290.

Kahn, A. J. (1974) An autoradingraphic analysis of the time of appearance of neurons in the developing chick neural retina. Dev. Biol. 38: $30-40$.

Kapfhammer, J. P., B. E. Grunewald, and J. A. Raper (1986) The selective inhibition of growth cone extension by specific neurites in culture. J. Neurosci. 6: 2527-2534.

Kohler, G., and G. Milstein (1976) Derivation of specific antibodyproducing tissue culture and tumor lines by cell infusion. Eur. J. Immunol. 6: 511-519.

Laemmli, U. K. (1970) Cleavage of structural proteins during the assembly of the head of bacteriophage T4. Nature 227: 680-685.

LaVail, J. H., and W. M. Cowan (1971) The development of the chick optic tectum. I. Normal morphology and cytoarchitectonic development. Brain Res. 28: 391-419.

I emmon, V. P., and S. C. McI oon (1986) The appearance of an I.1like molecule in the chick primary visual pathway. J. Neurosci. 6 : 2987-2994.

Matthew, W. D., and A. W. Sandrock (1987) Cyclophosphamide treatment used to manipulate the immune response for the production of monoclonal antibodies. J. Immunol. Methods 100: 73-82.

McLoon, S. C. (1984) Development of the retinotectal projection in chicks. In Organizing Principles of Neural Development, S. C. Sharma, ed., pp. 325-342, Plenum, New York.

McLoon, S. C. (1985) Evidence for shifting connections during development of the chick retinotectal projection. J. Neurosci. 5: 25702580.

Morest, D. K. (1970) The pattern of neurogenesis in the retina of the rat. Z. Anat. Entwickl.-Gesch. 131: 45-67.

O'Gorman, S., I. Kilty, and R. K. Hunt (1987) Healing and growth of half-eye "compound eyes" in Xenopus: Application of an interspecific cell marker. J. Neurosci. 7: 3764-3782. 
Prada, C., L. Puelles, and J. M. Genis-Galvez (1981) A golgi study on the early sequence of differentiation of ganglion cells in the chick embryo retina. Anat. Embryol. 161: 305-317.

Ramon y Cajal, S. (1911) Histologie du Systeme Nerveux de l'Homme et des Vertebres, Vol. 2 (1972 reprint), Instituto Ramón y Cajal, Madrid.

Rănớn y Cajal, S. (1929) Studies on Vertebrate Neurogenesis (revised and translated 1960, by L. Guth), Thomas, Springfield, ILL.

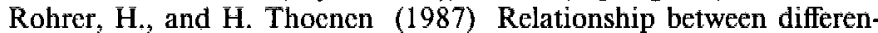
tiation and terminal mitosis: Chick sensory and ciliary neurons differentiate after terminal mitosis of precursor cells, whereas sympathetic neurons continue to divide after differentiation. J. Neurosci. 7 : $3739=3748$.

Rothman, T. P., M. D. Gershon, and H. Holtzer (1978) The relationship of cell division to the acquisition of adrenergic characteristics by developing sympathetic ganglion cell precursors. Dev. Biol. 65 322-341.

Rothman, T. P., L. A. Specht, M. D. Gershon, T. H. Joh, G. Teitelman,
V. M. Pickel, and D. J. Reis (1980) Catecholamine biosynthetic enzymes are expressed in replicating cells of the peripheral but not the central nervous system. Proc. Natl. Acad. Sci. USA 77:62216225 .

Sechrist, J. W. (1969) Neurocytogenesis. I. Neurofibrils, neurofilaments, and the terminal mitotic cycle. Am. J. Anat. 124: 117-134.

Tapscott, S. J., G. S. Bennett, and H. Holtzer (1981) Neuronal precursor cells in the chick neural tube express neurofilament proteins. Nature 292: 836-838.

Towbin, H., T. Staehelin, and J. Gordon (1979) Electrophoretic transfer of proteins from polyacrylamide gels to nitrocellulose sheets: Procedure and some applications. Proc. Natl. Acad. Sci, USA 76:43504354.

Turner, D. L., and C. L. Cepko (1987) A common progenitor for neurons and glia persists in rat retina late in development. Nature 328: 131-136.

Wetts, R., and S. E. Fraser (1988) Multipotent precursors can give rise to all major cell types of the frog retina. Science $239: 1142-1145$. 